\title{
Pregnancy and renal cyst hydatid disease: Case report
}

\author{
İlhan Gecit ${ }^{1 \star}$, Necip Pirincci ${ }^{1}$, Kerem Taken ${ }^{1}$, Recep Eryılmaz ${ }^{1}$, Hüseyin Özveren ${ }^{1}$ and \\ Serkan Deveci ${ }^{2}$
}

\author{
${ }^{1}$ Department of Urology, Faculty of Medicine, Yüzüncü Yıl University, 65100 Van/Turkey. \\ ${ }^{2}$ Department of Urology, Acıbadem Hospital, İstanbul/Turkey.
}

Accepted 13 January, 2012

\begin{abstract}
Hydatid cyst disease is an important health problem in many countries, including Turkey. While it can impact any organ, it is most often found in the lung and liver. Renal involvement is relatively rare. A diagnosis of renal cystic hydatidosis was established with ultrasound and magnetic resonance in a 22 year old patient who was 25 weeks pregnant after she presented with severe right flank pain. Albendazol was administered at a dose of $10 \mathrm{mg} / \mathrm{kg} / \mathrm{day}$. She was closely followed during her pregnancy. At 38 weeks, she gave birth to a healthy baby via vaginal delivery. Following her delivery, the cyst was resected. Post-operatively, she completed an 8 week course of albendazol at a dose of 10 $\mathrm{mg} / \mathrm{kg} / \mathrm{day}$. 1 year later, the patient has done well with no complications. We presented this case to highlight the lack of consensus in regards to the treatment of renal hydatid cyst disease in pregnancy.
\end{abstract}

Key words: Renal, pregnancy, hydatid cyst disease.

\section{INTRODUCTION}

Hydatid cyst disease is an important health problem in many countries including Turkey (Afşar et al., 1994). This parasitic infestation is caused by Echinococcus granulosus, Echinococcus multilocularis and Echinococcus vogeli. Adult forms attach themselves to the intestinal mucosa of primary hosts such as cats, dogs and wolves. Parasite eggs are excreted through feces and ingested by intermediate hosts such as man, sheep, and cattle. The life cycle is completed when contaminated hosts are again ingested by primary hosts. The disease state occurs only in intermediate hosts. Larvae complete their incubation period in the duodenum and penetrate the intestinal wall. They subsequently migrate to various organs through the blood. Most commonly, the disease is localized to the liver (70\%) and lung $(25 \%)$. It is also rarely localized to the kidneys (2 to $3 \%)$ Horchani et al. (2000). The renal lesions are most often single and one sided (85\%). Previous studies have shown that $95 \%$ of the lesions are between $4 \mathrm{~cm}$ and 18 $\mathrm{cm}$ and can easily enlarge to $10 \mathrm{~cm}$ before symptoms

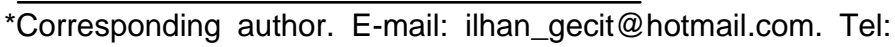
90432 2150470/6249. Fax: 904322167519. appear (Angolo et al., 1997).

\section{CASE}

A 22 year old female was admitted to the clinic with complaints of severe pain on her right side. She was 25 weeks pregnant at the time. Her past medical history was otherwise unremarkable. Her arterial tension(TA) was $120 / 70 \mathrm{mmHg}$, here respiratory rate was $18 / \mathrm{min}$, and here body temperature was $37.3^{\circ} \mathrm{C}$. Her physical exam was significant for right costovertebral angle tenderness. Abdominal ultrasonography showed a $8 \times 6.5 \mathrm{~cm}$ uniformly bounded mass cystic lesion with a solid component situated in the upper pole of the right kidney (Type III-IV Hydatid Cyst). There was also dilation of the pelvicaliceal system (Grade I-II Pelvicaliectasy). A single intrauterine pregnancy consistent with 25 weeks of gestation was also noted. Abdominal MR imaging was obtained to better visualize the lesion (Figure 1). Labs showed a white blood cell count of $11000 / \mathrm{mm}^{3}$ (lymphocyte $46.8 \%$, monocyte $1.5 \%$, neutrophil $46.3 \%$, eosinophil $2.4 \%$ ). An indirect hemugglutination assay was used to detect hydatid disease; anti-HIV, anti-HCV, and HbsAg tests were negative. No significant pathology was detected on 


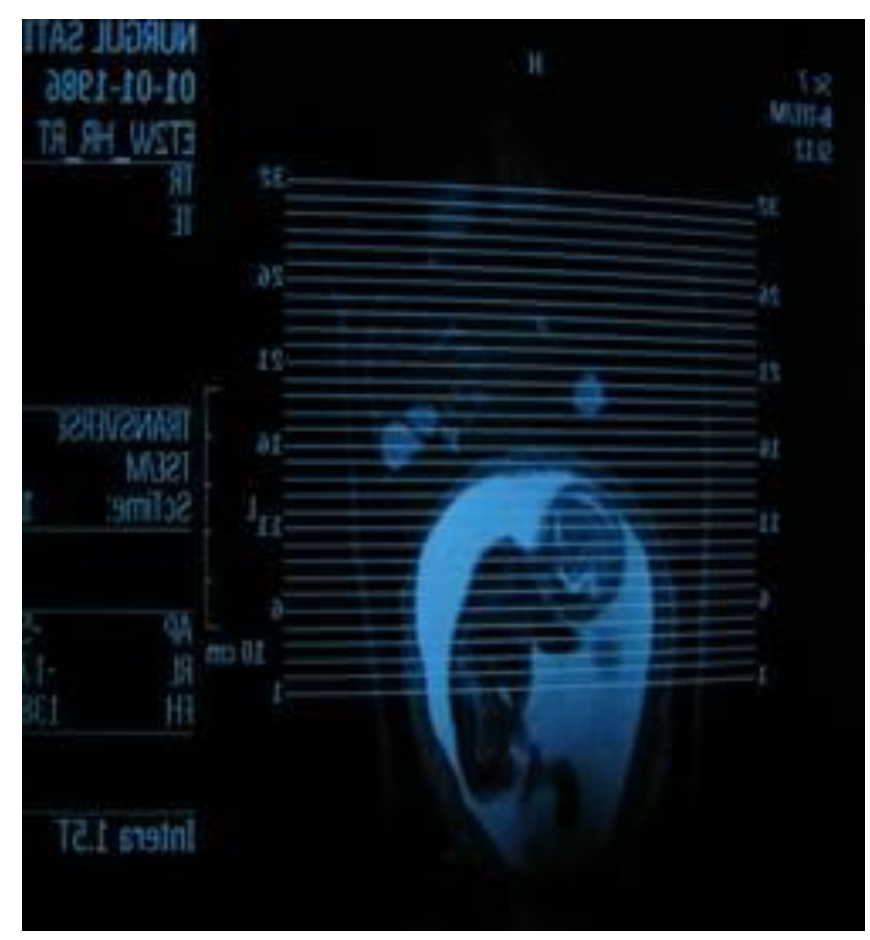

Figure 1. MR image of the hydatid cyst in the right kidney and the fetus in the uterus.

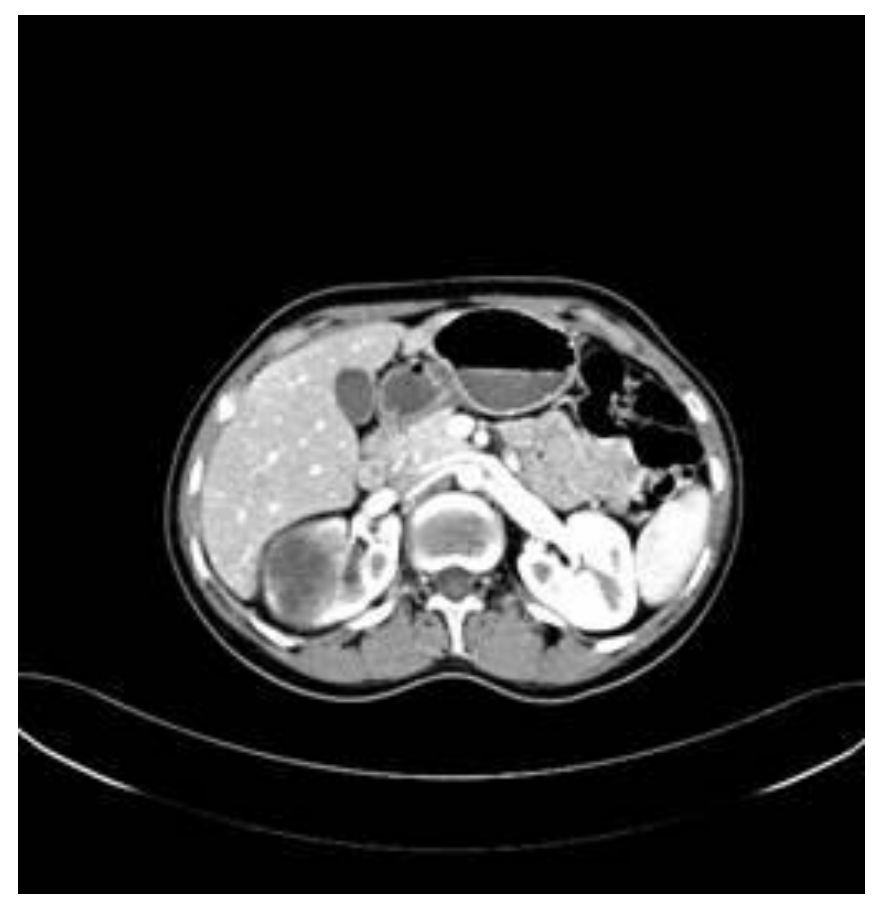

Figure 2. BT CT image taken after gestation (contrastenhanced).

the other abdominal organs. A ureteral stent was placed in the right ureter. A daily dose of albendazol (10 $\mathrm{mg} / \mathrm{kg} /$ day) was initiated. She was followed closely during her pregnancy with serial ultrasounds. She gave birth to a healthy baby by vaginal delivery at 38 of weeks gestation. Renal CT was performed during the postpartum period (Figure 2). Subsequently, the patient underwent operative resection of the cyst. During the procedure, hypertonic saline was injected into the cyst and allowed to sit for $15 \mathrm{~min}$. The kidney was spared.

An effort was made not to allow the contents of the cyst to spill into the surrounding tissues. Postoperatively, treatment with albendazol at a dose of $10 \mathrm{mg} / \mathrm{kg} / \mathrm{day}$ was continued for 8 weeks. Patient follow-up one year later showed that she had recovered well with absolutely no complications.

\section{DISCUSSION}

$90 \%$ of patients with hydatid cyst disease will have positive serological results. The ELISA method can be used to detect specific antigenes and immunocomplexes. The treatment involves both surgical and medical techniques (open surgery, percutaneous and laparoscopic). Surgical techniques are recommended as a first-line treatment. Cystectomy is a simple and reliable strategy in the treatment of renal hydatid cyst disease. It is applicable for total or subtotal surgical excision. If the cyst is proven or suspected to communicate with the collecting tubules, a partial nephrectomy is preferable. Albendazol is the drug of choice for medical treatment.

During pregnancy, the hydatid cyst can rapidly enlarge due to the suppression of cellular immunity and steroids secreted by the placenta. If the cyst ruptures, a severe allergic reaction to the contents of the cyst as well as significant hemorrhage from the cyst can occur. In both cases, this process can be fatal. In both cases this can be fatal. Only limited data have been published about the outcome and optimal treatment of hydatid cyst disease during pregnancy. Cyst drainage followed by early surgical intervention is the generally accepted method. Animal studies suggest that albendazol used in the first trimester of pregnancy can have teratogenic effects; however, it is thought to be safe in the second and third trimesters (Sahin et al., 2005; Saher et al., 2001; Can et al., 2003). Iyilikçi et al. (2006) presented the case of a pregnant woman at 16 weeks gestation who was treated with percutaneous drainage of a liver hydatid cyst and completed her pregnancy without any complications. Sahin et al. (2005) also published a case of hydatid cyst disease of the liver and pelvis treated at 15 weeks with a laparotomy. The patient was discharged without any complications during the remainder of her pregnancy (Sahin et al., 2005).

Finally, a report by Tertemiz et al. (2008) reported the case of a patient who was 20 weeks pregnant with hydatid cyst disease. Termination of the pregnancy and operative treatment were recommended, but the patient refused. She subsequently completed her pregnancy without difficulty but developed serious complications 
(ruptured cyst, pneumothorax and pleural effusion) shortly after delivery (Tertemiz et al., 2008).

\section{CONCLUSION}

Hydatid cyst disease is rarely localized to the kidneys. There is also limited experience with treatment of hydatid cyst disease in pregnant women. There are specific options for treatment including termination of the pregnancy and nephrectomy. Recent developments have revived the concept of nephro-sparing surgery. In our case, the patient was closely monitored during her pregnancy and gave birth to a healthy baby via vaginal delivery at the 38th week. She subsequently underwent a sub-total cystectomy during the postpartum period, and no complications were observed. We present this case to highlight the lack of consensus with regard to the treatment of renal hydatid cyst disease in pregnancy.

\section{REFERENCES}

Afşar H, Yağcı F, Aybastı N, Meto Ş (1994). Hydatid Disease of the Kidney. Br. J. Urol., 73: 17-22.

Angolo JC, Sanchez-Chapado M, Alfonso D, Jose E, Juan TC, Lope M (1997). Renal echinococcosis: Clinical Study of 34 cases. J. Urol., 157: 787-794.

Can D, Oztekin O, Oztekin O, Tinar S, Sanci M (2003). Hepatic and splenic hydatid cyst during pregnancy: A case report. Arch. Gynecol. Obstet., 268: 239-240.

Horchani A, Noviara Y, Khaier I, Attiyaovi F, Zribi AS (2000). Hydatid Cyst of the Kidney. Eur. Urol., 38: 461-467.

İyilikçi L, Balkan BK, Capar E (2006). Sedation for percutenaous treatment of hepatic hydatid cyst in a pregnant patient. Arch. Gynecol. Obstet., 274: 113-114.

Saher F, Srour MD, Joel Sayfan MD (2001). Echionococcosis of the spleen during pregnancy. IMAJ, 3: 290-291.

Sahin E, Nayki U, Sadık S (2005). Abdominal and pelvic hydatid disease during pregnancy. Arch. Gynecol. Obstet., 273: 184-191.

Sahin E, Nayki U, Sadık S (2005). Abdominal and pelvic hydatid diseaseduring pregnancy. Arch. Gynecol. Obstet., 273: 58-59.

Tertemiz KC, Gökçen B, Onen A, Akkoçlu A (2008). Pregnancy and hydatid cyst. Tuberk Toraks, 56: 96-99. 